\title{
Burst Firing and Spatial Coding in Subicular Principal Cells
}

\author{
어ean Simonnet ${ }^{1}$ and Michael Brecht ${ }^{1,2}$ \\ ${ }^{1}$ Bernstein Center for Computational Neuroscience Berlin, Humboldt-Universität zu Berlin, 10115 Berlin, Germany, and ${ }^{2}$ NeuroCure Cluster of Excellence, \\ Humboldt-Universität zu Berlin, 10099 Berlin, Germany
}

The subiculum is the major output structure of the hippocampal formation and is involved in learning and memory as well as in spatial navigation. Little is known about how neuronal diversity contributes to function in the subiculum. Previously, in vitro studies have identified distinct bursting patterns in the subiculum. Here, we asked how burst firing is related to spatial coding in vivo. Using juxtacellular recordings in freely moving male rats, we studied the bursting behavior of 102 subicular principal neurons and distinguished two populations: sparsely bursting $(\sim 80 \%)$ and dominantly bursting neurons $(\sim 20 \%)$. These bursting behaviors were not linked to anatomy: both cell types were found all along the proximodistal and radial axes of the subiculum and all identified cells were pyramidal neurons. However, the distinct burst firing patterns were related to functional differences: the activity of sparsely bursting cells showed a stronger spatial modulation than the activity of dominantly bursting neurons. In addition, all cells classified as boundary cells were sparsely bursting cells. In most sparsely bursting cells, bursts defined sharper firing fields and carried more spatial information than isolated spikes. We conclude that burst firing is functionally relevant to subicular spatially tuned neurons, possibly by serving as a mechanism to transmit spatial information to downstream structures.

Key words: border cell; cluster analysis; hippocampus; multiplexing; orientation

\section{Significance Statement}

The subiculum is the major output structure of the hippocampal formation and is involved in spatial navigation. In vitro, subicular cells can be distinguished by their ability to initiate bursts as brief sequences of spikes fired at high frequencies. Little is known about the relationship between cellular diversity and spatial coding in the subiculum. We performed high-resolution juxtacellular recordings in freely moving rats and found that bursting behavior predicts functional differences between subicular neurons. Specifically, sparsely bursting cells have lower firing rates and carry more spatial information than dominantly bursting cells. Additionally, bursts fired by sparsely bursting cells encoded spatial information better than isolated spikes, indicating that bursts act as a unit of information dedicated to spatial coding.

\section{Introduction}

The subiculum is the major output structure of the hippocampus, receiving its main inputs from CAl and sending divergent

Received June 26, 2018; revised Jan. 27, 2019; accepted Feb. 8, 2019.

Author contributions: J.S. and M.B. designed research; J.S. performed research; J.S. contributed unpublished reagents/analytic tools; J.S. analyzed data; J.S. and M.B. wrote the first draft of the paper; J.S. and M.B. edited the paper; J.S. and M.B. wrote the paper.

This work was supported by Humboldt-Universität zu Berlin, Bernstein Center for Computational Neuroscience Berlin, NeuroCure Cluster of Excellence, Deutsche Forschungsgemeinschaft (SPP 1665, BR 3479/12-1), Deutsche Forschungsgemeinschaft Gottfried Wilhelm Leibniz Preis. We thank Edith Chorev, Rajnish Rao, Juan Ignacio Sanguinetti-Scheck, Konstantin Hartmann, and Peter Bennett for discussion and comments on the paper; and Andreea Neurkirchner, Undine Schneewei $\beta$, Juliane Diederichs, Tanja Wölk, Maik Kunert, and Arnold Stern for outstanding technical support.

The authors declare no competing financial interests.

Correspondence should be addressed to Jean Simonnet at jean.simonnet@bccn-berlin.de or Michael Brecht at michael.brecht@bccn-berlin.de.

https://doi.org/10.1523/JNEUROSCl.1656-18.2019

Copyright $\odot 2019$ Simonnet and Brecht

This is an open-access article distributed under the terms of the Creative Commons Attribution License Creative Commons Attribution 4.0 International, which permits unrestricted use, distribution and reproduction in any medium provided that the original work is properly attributed. outputs to many subcortical and cortical areas (Amaral and Witter, 1989; Witter, 2006). The subiculum is involved in spatial learning and memory (Morris et al., 1990; Galani et al., 1998; Roy et al., 2017; Cembrowski et al., 2018) but has not been the major focus of studies analyzing hippocampal function in spatial navigation.

In vivo, the vast majority of subicular neurons carry positional information (Sharp and Green, 1994; Brotons-Mas et al., 2010, 2017) but subicular firing fields are not as well defined as those of CA1 place cells or the eye-catching medial entorhinal grid cells (O'Keefe and Dostrovsky, 1971; Hafting et al., 2005), because of higher basal firing rates in the subiculum compared with cells from these two other areas. Nevertheless, the subiculum spatial signals could play a determining role in forming and stabilizing other spatial codes. Subicular neurons seem to generalize across different environments because firing fields of subicular cells do not remap in response to novel environments, nor do they remap in darkness (Sharp, 1997; Lever et al., 2009; Brotons-Mas et al., 2010). The encoding of environmental boundaries, via boundary 
cells, is a prominent feature of the subiculum (Barry et al., 2006; Lever et al., 2009; Lee et al., 2018), which is likely to play a role in forming and anchoring spatial maps in adult animals (O'Keefe and Burgess, 1996; Hartley et al., 2000; Barry et al., 2006; Hardcastle et al., 2015; Krupic et al., 2015) and from early stages of development (Bjerknes et al., 2014; Muessig et al., 2015).

Determining how the subiculum generates its own activity and could influence spatial signals in other areas requires further investigation, more specifically at the level of the microcircuit. Indeed, the microcircuitry underlying spatial tuning in the subiculum is largely unresolved. The subicular anatomy is not as clearly stratified as the stratum pyramidale of CA1 (proximal to subiculum) and also lacks the elaborate lamination of six-layered cortical structures such as the presubiculum (distal to subiculum). The analysis of cell morphology indicates some internal structure (O'Mara, 2005) as well as laminar or modular organization based on long-range connectivity (Naber and Witter, 1998; Ishizuka, 2001; Witter, 2006; Y. Kim and Spruston, 2012). In vitro, subicular principal neurons may be distinguished by their firing patterns: some are intrinsic bursting (from 45 to $80 \%$ ) and others are regular spiking cells (Greene and Totterdell, 1997; Staff et al., 2000). Bursting relates to subicular anatomy; deeper cells as well as cells located on the distal part are more likely to be intrinsic bursting neurons (Greene and Totterdell, 1997; E. Harris et al., 2001; Y. Kim and Spruston, 2012; Cembrowski et al., 2018). However, how bursting relates to subicular function remains mostly unresolved, even though a few functional correlates of bursting have been suggested. First, the biophysical properties of subicular cells could be predicted by their efferent target area (Y. Kim and Spruston, 2012; Cembrowski et al., 2018), suggesting that intrinsic bursting or regular spiking cells might generate different streams of information (Cembrowski et al., 2018). Lastly, local connectivity and recruitment by sharp wave ripples suggested distinct roles for regular spiking and intrinsic bursting cells in the subicular microcircuit function (Böhm et al., 2015).

Here, we asked how subicular bursting relates to spatial coding in vivo. We took advantage of high-resolution juxtacellular recordings, which enabled us to reliably resolve small amplitude spikes; especially those resulting from sodium-channel inactivation during bursts. Using this technique in freely moving rats we asked: (1) Can bursting patterns be used to classify subicular neurons in vivo as in vitro? (2) How does the burstiness of discharges relate to spatial coding? (3) Do bursts and isolated spikes convey different types of information? We classified cells based on their burstiness and found that sparsely bursting cells are more spatially modulated than dominantly bursting cells. In addition, we found that all subicular boundary cells were sparsely bursting cells. In a large fraction of spatially modulated neurons $(34 / 51,66 \%)$, we found that bursts encoded position significantly better than isolated spikes. Here, bursts are distinct units containing more spatial information than isolated spikes. Because bursts and isolated spikes are differently encoded by short-term synaptic dynamics, our results imply that spatial information should be transmitted more effectively by facilitating synapses to downstream areas.

\section{Materials and Methods}

All experimental procedures were performed according to German guidelines on animal welfare.

Juxtacellular recordings in freely moving rats. Experimental procedures for obtaining juxtacellular recordings in freely moving rats were performed similarly to earlier publications (Tang et al., 2014). Recordings were made in 40 male Long-Evans rats (150-350 g) maintained in a $12 \mathrm{~h}$ light/dark phase and recorded during the dark phase. Surgical procedures were all performed under ketamine $(80 \mathrm{mg} / \mathrm{kg})$ and xylazine $(10$ $\mathrm{mg} / \mathrm{kg}$ ) anesthesia. Rats were implanted with a head-implant including a metal post for head-fixation, a placement of a miniaturized preamplifier coupled to two LEDs (red and blue), and a protection cap. To target the dorsal subiculum, a plastic ring was glued to the skull surface $5.7-6 \mathrm{~mm}$ posterior to bregma and $2.9-3.2 \mathrm{~mm}$ left to midline. The craniotomy and the positioning of the metal post for holding the miniaturized micromanipulator (Kleindiek Nanotechnik) were done either during the same surgery or in a subsequent surgery. After implantation, rats were allowed to recover and were habituated to head-fixation for 2-5 d. Rats were trained to forage for chocolate pellets in an open-field arena, a $70 \times 70 \times$ $50 \mathrm{~cm}(\mathrm{WDH})$ box with a white polarizing cue card on one of the walls, before and after implantation (3-7 d, multiple sessions of 15-20 min each per day).

For recordings, rats were head-fixed and the miniaturized micromanipulator and preamplifier were secured to the metal posts.

Glass pipettes with resistance $4-6 \mathrm{M} \Omega$ were filled with Ringer solution ( $n=103 / 109$ ) containing the following (in $\mathrm{mm}$ ): $135 \mathrm{NaCl}, 5.4 \mathrm{KCl}, 5$ HEPES, $1.8 \mathrm{CaCl}_{2}$, and $1 \mathrm{MgCl}_{2}$; or patch-clamping internal solution ( $n=6 / 109$ ) containing the following (in $\mathrm{mM}$ ): $130 \mathrm{~K}$-gluconate, $10 \mathrm{Na}$ gluconate, 10 HEPES, 10 phosphocreatine, 4 MgATP, 0.3 GTP, $4 \mathrm{NaCl}$. In both cases, the $\mathrm{pH}$ was adjusted to 7.2 , neurobiotin $(1-2 \%)$ was added to the solution, and the osmolality was adjusted to $285-305 \mathrm{mmol} / \mathrm{kg}$. The patch-clamp solution was used to perform juxtacellular stimulations, of which the results are not used in the context of the current study. The firing rate and the firing pattern were not different between subicular cells recorded with the two different solutions; therefore, the two subsets have been merged and considered as one group.

The glass recording pipette was advanced into the brain; and a thick agarose solution (3-4\% in Ringer) was applied into the recording chamber for sealing the craniotomy and for stabilization. Animals were then released into the behavioral arena and juxtacellular recordings were established while animals were freely exploring the environment. The juxtacellular signals were acquired with an ELC-03XS amplifier (NPI electronic) and digitized with a Power 1401 data-acquisition interface coupled to Spike2-v7 (CED, Cambridge Electronic Design) where signals were sampled at $50 \mathrm{kHz}$. The arena was filmed from above with a color camera so the position of red and blue LEDs could be tracked to determine the animal's location and head-direction. All signal processing and analyses were performed in MATLAB (MathWorks).

Anatomy. The neurobiotin in the pipette allowed us to perform juxtacellular labeling at the end of the recording session (Pinault, 1996; Tang et al., 2014). A number of recordings were either lost before the labeling could be attempted, or the recorded neurons could not be clearly identified, but the location of all the cells included in the current study was positively assigned to the subiculum. Ten to $30 \mathrm{~min}$ after the labeling protocol, the animals were killed by overdose of isoflurane, and perfused transcardially with 0.1 м PBS followed by $4 \%$ paraformaldehyde solution. Brains were dissected out of the animal's skull and were placed in the same $4 \%$ paraformaldehyde solution for $12-24 \mathrm{~h}$, and then in $0.1 \mathrm{M}$ PB. Parasagittal sections $(60-150 \mu \mathrm{m}$ thick) were obtained using a vibratome (Mikrom, HM 650 V, ThermoFisher Scientific). Sections were washed in PBS $0.1 \mathrm{~m}(2 \times 10 \mathrm{~min}$, agitation $60 \mathrm{rpm})$, in PBS $0.1 \mathrm{~m}$ containing $0.5 \%$ Triton $(2 \times 10 \mathrm{~min}$, agitation $60 \mathrm{rpm})$, and then preincubated in PBS $0.1 \mathrm{~m}$ containing $2.5 \%$ BSA and $0.5 \%$ Triton $(1 \mathrm{~h}$ at room temperature, agitation $60 \mathrm{rpm}$ ). Sections were then incubated with PBS $0.1 \mathrm{~m}$ containing 1:500 AlexaFluor488-streptavidin, 1\% BSA and $0.5 \%$ Triton (overnight at $4^{\circ} \mathrm{C}$, agitation $60 \mathrm{rpm}$ ), revealing the neurobiotin. Sections were then washed in PBS $0.1 \mathrm{M}(2 \times 10 \mathrm{~min}$, agitation 60 $\mathrm{rpm})$. Sections were not mounted, but were instead briefly transferred on slides for acquiring fluorescent signals (Leica DM 5500B) and then kept in PBS $0.1 \mathrm{M}$ containing $0.01 \mathrm{M}$ sodium azide at $4^{\circ} \mathrm{C}$ for short term storage (max 1-2 months).

We distinguished three levels along each one of the proximodistal and radial axes (depth) of the subiculum. From CA1, the first $2 / 5$ was considered as proximal subiculum, the last $2 / 5$ as distal subiculum, and the $1 / 5$ in the middle as an intermediate part. We did not assign recordings from the most superficial $2 / 5$ of the subiculum, mostly because it mainly 
contains fibers and interneurons. We defined the next three $1 / 5$ as superficial, middle, and deep subiculum. Ideally, recovered cells or recording sites could be assigned to a proximodistal and depth level of the subiculum $(n=34 / 102)$. Only the proximodistal level of the recordings could be assigned using the pipette track location $(n=60 / 102)$. In some cases ( $n=8 / 102$ ), the pipette tracks had penetrated the subiculum following an angle that made the assignment impossible (e.g., proximal in the deeper part and distal in the most superficial part).

To reconstruct the morphology of recovered cells, we converted the fluorescent signals to a dark diaminobenzidine (DAB) precipitate so we could use a bright-field microscope (Olympus, BX 51) coupled with Neurolucida (MBF Bioscience) for reconstructing cellular morphologies. The conversion procedure was performed as follows: sections were washed in TBS (tris- $\mathrm{HCl} 0.05 \mathrm{M}, 0.9 \% \mathrm{NaCl})(1 \times 10 \mathrm{~min}$, agitation 60 $\mathrm{rpm}$ ) and then in TBS containing $0.3 \%$ Triton (TBS-X, $3 \times 10 \mathrm{~min}$ ); sections were then incubated with TBS-X containing 20\% BSA for 20 min, quickly washed in TBS-X, and then incubated in the TBS-X containing 1:100 of the B solution of the Vectastain ABC-kit (Biozol; 4-6 h at room temperature, agitation $60 \mathrm{rpm}$ ). Sections were then incubated in TBS-X containing 1:100 of the A-B solutions (from the Vectastain ABCkit) overnight at $4^{\circ} \mathrm{C}$, then washed in TBS $(1 \times 10 \mathrm{~min})$ and in $\mathrm{PB} 0.1 \mathrm{M}$ $(2 \times 10 \mathrm{~min})$; then, sections were incubated in a pre-staining solution composed of $\mathrm{PB} 0.1 \mathrm{M}$ containing $0.004 \% \mathrm{NH}_{4} \mathrm{Cl}, 0.2 \%$ glucose, $0.004 \%$ $\mathrm{NH}_{4} \mathrm{NiSO}_{4}$ and 5.5\% 3,3'-DAB (20 min, darkness, agitation $60 \mathrm{rpm}$ ). The final step of the procedure was performed by incubating the sections with a staining solution (pre-staining solution $+2.4 \mathrm{U} / \mathrm{ml}$ of glucose oxidase) for 20-60 min at room temperature and then stopping the reaction by washing with $\mathrm{PB} 0.1 \mathrm{M}(3 \times 10 \mathrm{~min})$. Sections were mounted in a non-aqueous medium (e.g., Eukitt, Sigma-Aldrich) to prevent fainting of Ni-precipitates.

Spike and bursts detection. For spike detection, the raw signals were filtered (0.3-6 kHz, zero phase bandpass Butterworth filter of order 8). Transients were then detected using a threshold of 2.0 times the root mean square (rms) of the signal. High amplitude artifacts, because of behaviors like grooming, could increase the rms value significantly and prevent the detection of the smallest transients; the values in a window of $2.0 \mathrm{~ms}$ around these artifacts were therefore clipped and replaced by zeros. A second step for separating spikes from noise consisted of calculating the principal components of the transients followed by manually clustering the events into spikes and noise. This cleaning step was first performed on filtered waveforms and subsequently on raw waveforms. Eventually, the accuracy of spike detection was visually checked, scrolling throughout the whole recording. The cleaning step was repeated until the detection was optimal (minimizing false-positives and -negatives).

Finally, spikes were categorized as belonging to a burst if the interval from the prior spike and/or to the next spike was shorter than a threshold set at $6 \mathrm{~ms}$. One burst was therefore defined as a group of spikes $(\geq 2)$ interleaved with $<6 \mathrm{~ms}$. We calculated the proportion of bursts with $>2$ spikes as well as the mean spike count per burst as measures of burst strength. The burst time stamp was set to that of the first spike in a burst. The intraburst interval was set as the mean interspike interval (ISI) during bursts.

Spike waveform analysis. The raw signals were filtered $(6 \mathrm{kHz}$, zero phase low-pass Butterworth filter of order 8) to minimize high-frequency noise. Spike shape parameters were determined based on the spike average waveform calculated from these low-pass filtered traces. Before the calculation of the average spike, the single waveforms had to be properly aligned. To this end, every spike waveform was oversampled at $1000 \mathrm{kHz}$ using a spline interpolation to better estimate its shape. Signal-to-noise ratios often differed between recordings and with it, the spike amplitude. To compare spike shape parameters between cells, the waveform was normalized so that the rising amplitude was $1 \mathrm{mV}$. We then calculated the derivative of each waveform. The threshold was set to the first sample, where both the voltage and its derivative were at least $5 \%$ of their maximal value. The rising amplitude $(\mathrm{mV})$ was set to the difference of potential between the peak and the threshold voltage. The afterhyperpolarization was set to the point at minimum voltage after the peak, when the derivative $\geq 0$. The spike duration was set to the threshold-toafterhyperpolarization duration.
Spike accommodation is classically defined as a reduction in the amplitude of subsequent spikes fired within a burst. Here, it was calculated as the ratio of amplitudes (from peak to afterhyperpolarization) between the second and the first spikes of each burst. An accommodation of 1 means that there was no decrease of spike amplitude; 0.5 means that amplitude was divided by 2 .

Putative fast-spiking interneurons $(n=6 / 109)$ were identified based on four criteria: their high firing rate (typically $>30 \mathrm{~Hz}$ ), their spike duration (typically to $0.6 \mathrm{~ms}$ ), their high maximum derivative (typically $>9 \mathrm{mV} / \mathrm{ms}$ ), and low minimum derivative (typically $<-9 \mathrm{mV} / \mathrm{ms}$ ). Cells meeting at least three of these four criteria were considered as fast-spiking interneurons and were not used for the subsequent analyses.

Analysis of burstiness. In vivo, firing pattern features and burstiness are commonly addressed using methods relying on either distribution of ISIs or spike autocorrelations.

The first set of methods, based on the distribution of ISIs, has previously been used to study burstiness in the subiculum (Sharp and Green, 1994; Lever et al., 2009; Brotons-Mas et al., 2010) and other areas such as parahippocampal cortices (Ebbesen et al., 2016). In principle, ISI distribution analyses estimate burstiness by either determining a bursting index, being the proportion of ISI below the bursting threshold (here we used $6 \mathrm{~ms}$ ) or by classifying the cells after performing a principal component analysis of the ISI histogram matrix. The limit of these analyses is that ISI interval distribution might overestimate burstiness for cells with elevated firing rates, and therefore they report a variability that correlates with cells' firing rates (S. M. Kim et al., 2012).

The second set of methods rely on spike autocorrelations (S. M. Kim et al., 2012; Latuske et al., 2015; Coletta et al., 2018). Latuske et al. (2015), as well as Coletta et al. (2018) both used principal component analysis of the first $12 \mathrm{~ms}$ of the spike-autocorrelation to classify the cells in different bursting groups. S. M. Kim et al. (2012) calculated a bursting index as the ratio of the integrated power of the autocorrelogram between 1 and $6 \mathrm{~ms}$ normalized by the overall power between 1 and $20 \mathrm{~ms}$. Using these methods does not bias the burstiness estimation for high firing neurons (S. M. Kim et al., 2012). However, we realized that it could overestimate the bursting probability of neurons with low firing rates and occasional bursts because only the first few milliseconds of the spike autocorrelation were considered.

Our classification of subicular principal cells in distinct subpopulations was inspired by the two different sets of methods. We used histograms of the logarithm of ISIs (logISI) instead of using only the initial bins of the ISI-histograms (e.g., 1-60 ms; Ebbesen et al., 2016). It has been used by others for burst analysis (Ko et al., 2012) and depicts the whole ISI distribution with a good focus on short intervals. Specifically, we defined 60 bins regularly spaced between $\log (0.0005)$ and $\log (10)$, so as to have a distribution of intervals between 0.0005 and $10 \mathrm{~s}$. When $\operatorname{logISI}$ histograms were used in figures (Figs. 1,2), the $\operatorname{logISI} x$-axis values were replaced by the corresponding ISI values for more clarity. Principal component analysis was done on both the logISI frequency matrix and for the 1-20 ms lag frequency matrix (resolution of $1 \mathrm{~ms}$ ). We focused on the first principal components (PCs) explaining most of the variance (Fig. 1C,D).

$\mathrm{PC} 1, \mathrm{PC} 2$ and $\mathrm{PC} 3$ of the logISI histograms $\left(\mathrm{PC}_{\mathrm{ISI}} 1, \mathrm{PC}_{\mathrm{ISI}} 2\right.$, and $\mathrm{PC}_{\mathrm{ISI}} 3$ ) explained, respectively, 35,29 , and $15 \%$ of the total variance (approximately $78 \%$ total; Fig. $1 C$ ). PC1 and PC2 of the spike autocorrelation matrix $\left(\mathrm{PC}_{\mathrm{AC}} 1\right.$ and $\left.\mathrm{PC}_{\mathrm{AC}} 2\right)$ explained 68 and $22 \%$ of the total variance $(90 \%$ total; Fig. $1 D)$. The loading of ISI and lags into these first components are represented in Figure 1, E and $F$, respectively. These first components from each PCA were used to represent the firing pattern features of all recorded neurons in a 5-dimensional space. We then generated a cluster tree using Ward's method on the normalized Euclidean distance between cells (Fig. 2A). The Ward's method establishes hierarchical clusters by iteratively grouping the two closest observations or groups of observations together. Consequently, cells with very similar firing patterns are primarily grouped together and groups with very different properties are linked at the end of the procedure (Ward, 1963). Two clusters strikingly emerged from the agglomerative cluster tree (Fig. $2 A$ ), defining two groups of neurons that we named sparsely bursting cells and dominantly bursting cells based on their potency to initiate 
bursts (see Results; Fig. 1). We compared our classification based on the first component of the spike autocorrelation only. The last resulted in a less relevant classification, where more groups should be defined to isolate the most bursting cells from the others (data not shown).

Analysis of spatial information. The position of the rat was defined as the midpoint between the two head-mounted LEDs. A running speed threshold $(3 \mathrm{~cm} / \mathrm{s})$ was applied for isolating periods of rest from navigation. For generating color-coded firing maps, space was discretized into pixels of $2.5 \times 2.5 \mathrm{~cm}$. For each such pixel the occupancy $o(x)$ was calculated as follows:

$$
o(x)=\sum_{t} w\left(\left|x-x_{t}\right|\right) \Delta t,
$$

where $x_{t}$ is the position of the rat at time $t, \Delta t$ the inter-frame interval, and $w$ a Gaussian smoothing kernel with $\sigma=5 \mathrm{~cm}$. Then, the firing rate $r$ was calculated for each pixel $x$ :

$$
r(x)=\frac{\sum_{i} w\left(\left|x-x_{i}\right|\right)}{o},
$$

where $x_{i}$ is the position of the rat when spike $i$ was fired.

For recordings in which the animal's trajectory covered at least $60 \%$ of the open field ( $n=$ $84 / 102$ ), we calculated the spatial information rate, $I$ (bits/spike), from the spike train and rat trajectory as follows:

$$
I=\frac{1}{T} \int r(x) \log _{2} \frac{r(x)}{\bar{r}} o(x) d x,
$$

where $r(x)$ and $o(x)$ are the firing rate and occupancy as a function of a given pixel $x$ in the rate map. $\bar{r}$ is the overall mean firing rate of the cell, and $T$ is the total duration of a recording session (Skaggs et al., 1993).

A cell was declared to have a significant amount of spatial information if the observed spatial information rate exceeded the 95th percentile of a random distribution of values of $I$ obtained by circular shuffling. A circular timeshift $t^{\prime} \in[0 T]$ was applied to the recorded spike train timestamp (von Heimendahl et al., 2012; Bjerknes et al., 2014), $T$ being the total duration of the recording session. This procedure maintains the temporal structure of the cell's firing but alters the spatial distribution of spikes and therefore $I$. It was performed 1000 times to generate the random distribution of $I$ that was used to determine the significance of spatial information.

Analysis of boundary cells. To determine whether subicular spatial neurons could be classified as border cells, we computed border scores (Solstad et al., 2008; Bjerknes et al., 2014) as follows. Firing fields were detected on the rate maps as a collection of neighboring pixels covering at least $100 \mathrm{~cm}^{2}$ (16 pixels) with a minimum rate of $1 / 3$ of the firing rate range. Only fields with a peak firing of at least $2 / 3$ of the firing rate range were considered. For each cell, we could detect the main and also second-
A
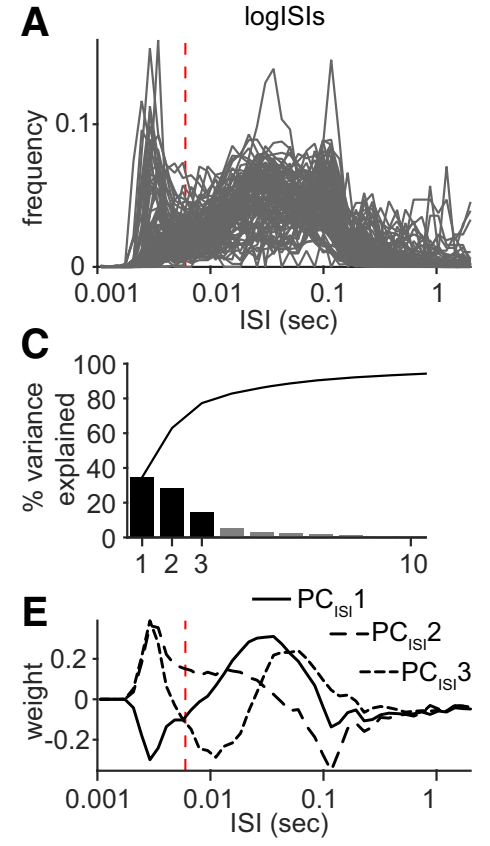

G

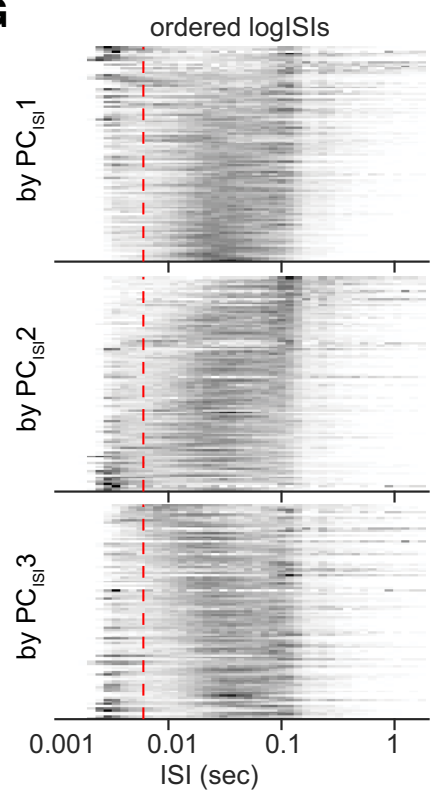

B
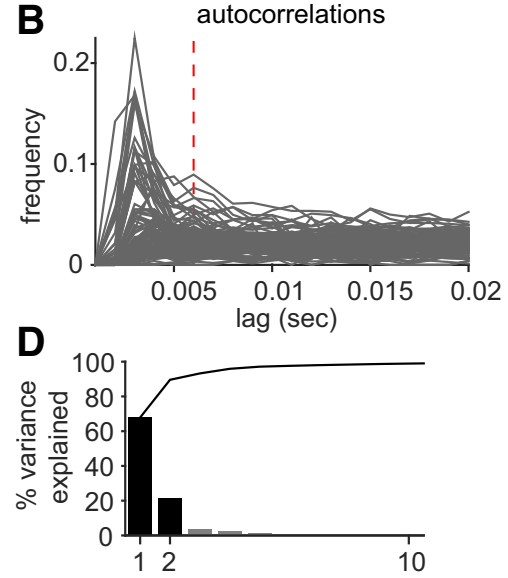

$F$

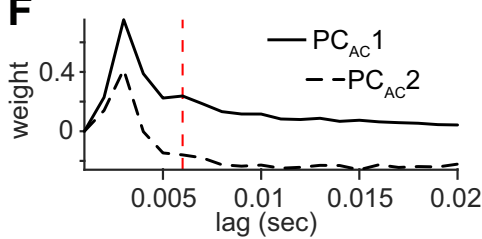

H

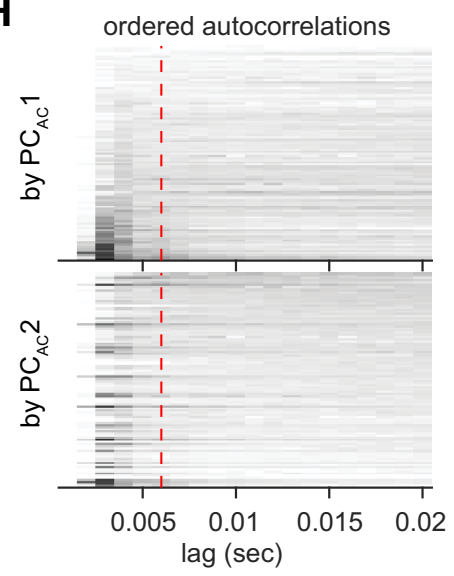

Figure 1. Principal component analyses of ISI distributions and spike autocorrelations during navigation. $\boldsymbol{A}$, Top, Histogram of the logISI for all subicular principal cells $(n=102)$. The values of the $x$-axis have been replaced by the corresponding interval values in seconds. $\boldsymbol{B}$, Top, Spike autocorrelation for all subicular principal cells $(n=102)$. The plot is normalized so the 0 ms-lag value is equal to 1 (out of the axis range here). The vertical dashed line is placed at $6 \mathrm{~ms}$. Only navigating periods have been considered for these analyses (rat's speed $>3 \mathrm{~cm} / \mathrm{s}$ ). C, Percentage of variance explained by the 10 first principal components of logISI histogram. $P C_{|S|} 1, P C_{|S|} 2$ and $P C_{|S|} 3$ explain, respectively, 35, 29, and $15 \%$ of the total variance, so approximately $78 \%$ in total. $D$, Percentage of variance explained by the 10 first principal components of spike autocorrelations. $P C_{A C} 1$ and $P C_{A C} 2$ explain, respectively, 68 and $22 \%$ of the total variance, so $90 \%$ in total. $\boldsymbol{E}$, Loading of the logISI bins into the first three principal components $\left(P C_{|S|} 1, P C_{|S|} 2\right.$ and $\mathrm{PC}_{\mathrm{ISI}} 3$ ) of the logISI histogram matrix. The vertical dashed line is placed at $6 \mathrm{~ms}$ corresponding to our threshold for burst firing. The short intervals $(<6 \mathrm{~ms}$ ) are similarly loaded in the first three components in contrast with the more delayed intervals. $\boldsymbol{F}$, The autocorrelation lags are loaded according to similar patterns into the first two principal components $\left(P C_{A C} 1\right.$, and $\left.P C_{A C} 2\right)$. $G$, The logISI histogram frequency matrix has been ordered according to values on $P C_{|S|} 1, P C_{|S|} 2$, and $P C_{|S|}$, and plotted in grayscale. One line is one cell; dark values correspond to high frequencies and light values to low frequencies. Cells with an initial peak tend to be distributed on one side (top or bottom), but not clearly grouped together. For each plot, a structure emerges in the delayed ISI range. Using the three first principal components of the logISI frequency matrix seems biologically relevant because they all depict both bursting and other discharge patterns, such as firing rates or theta modulation (peak $\sim 0.1 \mathrm{~s}$ ). $\boldsymbol{H}$, The spike autocorrelation frequency matrix has been ordered according to values on $P C_{A C} 1$ and $P C_{A C}$, and plotted in grayscale. One line is one cell; dark values correspond to high frequencies and light values to low frequencies. $P C_{A C} 1$ is clearly a good parameter to classify cells according to burstiness as cells with an initial peak $(<6 \mathrm{~ms})$ are grouped together at the bottom of the color plot. $P C_{A C} 2$ is not as good for predicting bursting behavior, even though a few cells with an initial peak can be found again at the bottom of the color plot. 
A

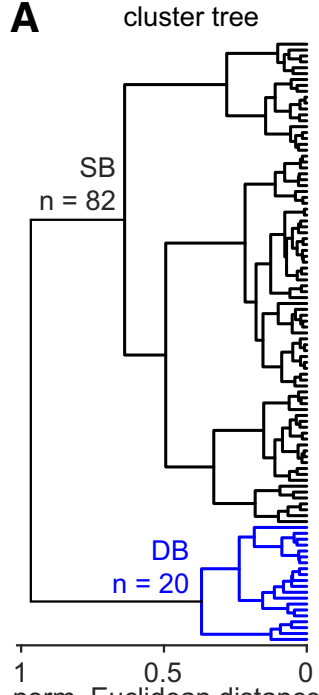

norm. Euclidean distance

D
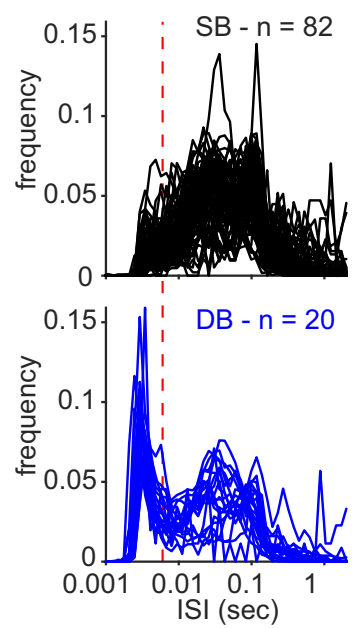

B logISI histograms

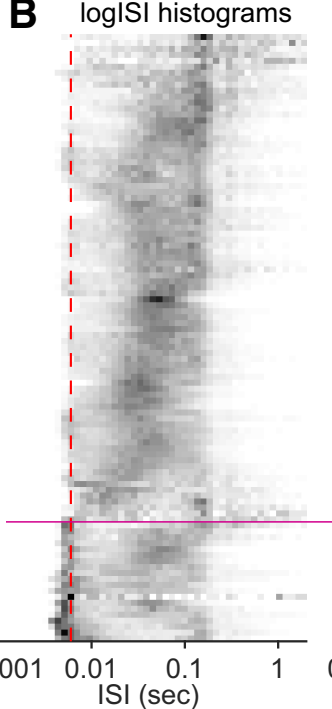

E
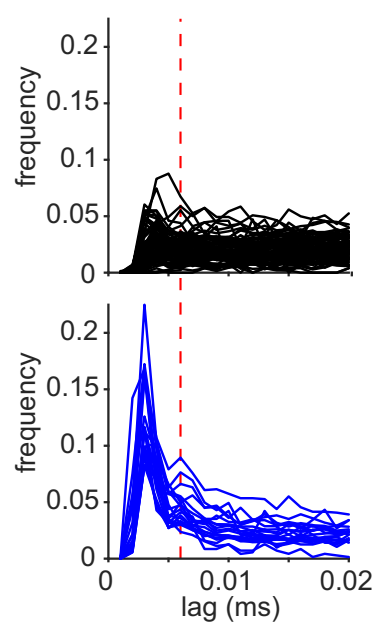

C autocorrelations

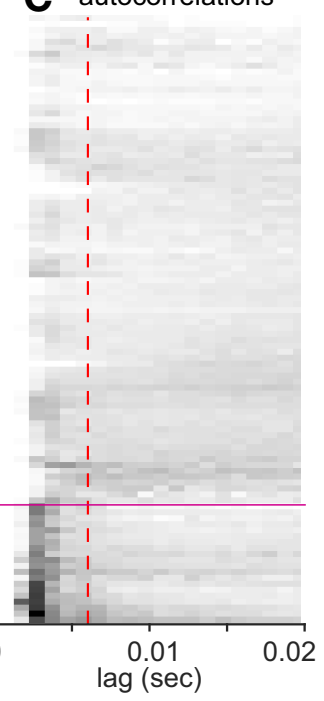

$\mathbf{F}$

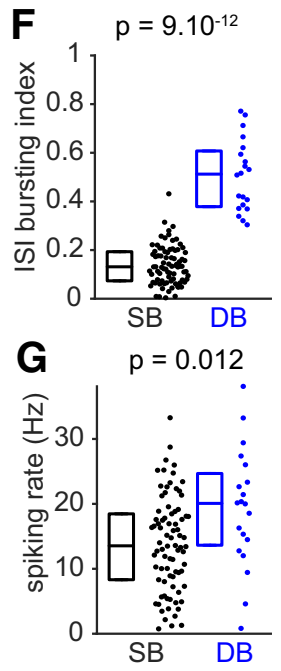

Figure 2. Classification of subicular principal cells based on their firing patterns during navigation. $A$, Hierarchical cluster tree of subicular principal cells based on the logISI and spike autocorrelation principal component analyses. The Ward's method, an agglomerative hierarchical clustering procedure was used to generate the cluster tree based on normalized Euclidean distance between cells in a 5-dimensional space, defined by $\mathrm{PC}_{|S|} 1, \mathrm{PC}_{|S|} 2, \mathrm{PC}_{|S|} 3, \mathrm{PC}_{\mathrm{AC}}$, and $\mathrm{PC}_{\mathrm{AC}}$ 2. The black branch corresponds to $\mathrm{SBs}$ and the blue branch corresponds to DBs. $B, C, \log |S|$ histogram and spike autocorrelation frequency matrices have been ordered as on the cluster tree in $\boldsymbol{A}$ and are represented in grayscale plots (black, high values; white, low values). The vertical dashed red lines are positioned at $6 \mathrm{~ms}$. Horizontal magenta lines show the cluster separation on the color plots. Cells with a prominent initial peak in logISI histogram and spike autocorrelation are grouped at the bottom of the representations and correspond to dominantly bursting cells. $D$, logISI histograms for SBs ( $n=82$; top) and DBs ( $n=20$; bottom). Note the prominent initial peak for dominantly bursting cells, absent for sparsely bursting cells, which highlights a higher proportion of low intervals corresponding to prominent burst firing. $E$, Spike autocorrelations for sparsely bursting cells $(n=82$, top) and dominantly bursting cells $(n=20$, bottom). As for the logISI histogram, note the prominent initial peak for dominantly bursting cells, absent for sparsely bursting cells. $\boldsymbol{F}$, ISI-based bursting index corresponding to the proportion of ISIs $<6 \mathrm{~ms}$ is significantly higher for dominantly bursting cells. $\boldsymbol{G}$, Spiking rate $(\mathrm{Hz})$ is significantly higher for dominantly bursting cells. Statistics: two-tailed Mann-Whitney $U$ test; box plots showing median and interquartile ranges.

ary fields when they were present. For each detected field, the average rate $\left(\right.$ rate $\left._{\text {field }}\right)$ and the average distance from the closest wall (dist field $_{\text {) }}$, as well as the linear distance covered along the wall ( $\operatorname{cov}_{\text {field }}$, average on the two first lines of pixels along the wall) were calculated. Each $\left(\mathrm{bs}_{\text {field }}\right)$ was then calculated as follows:

$$
b s_{\text {field }}=\frac{\operatorname{cov}_{\text {field }}-\text { dist }_{\text {field }}}{\operatorname{cov}_{\text {field }}+\text { dist }_{\text {field }}},
$$

$\mathrm{bs}_{\text {field }}$ values ranged from -1 to $1,-1$ for fields that do not cover any wall, and 1 for fields that would perfectly line-up along one of the walls.
We calculated each cell's border score $\left(\mathrm{bs}_{\text {cell }}\right)$ by normalizing the contribution of each field $f$ to their average rate:

$$
b s_{\text {cell }}=\frac{\sum_{f}\left(b s_{\text {field }} \times \text { rate }_{\text {field }}\right)}{\sum_{f} \text { rate }_{f i e l d}} .
$$

Fields with higher rates have higher contribution on the $\mathrm{bs}_{\text {cell }}$. Border scores also ranged from -1 to 1 and are typically high for stereotypical boundary cells, with firing fields covering one or several boundaries. We tested the significance of border scores following the same procedure as for spatial information.

Statistical analyses. We always show all data points on our population data plots. Boxplots always show medians and interquartile ranges.

In many cases, the significance of the difference observed between distinct groups was assessed with nonparametric tests only. Twotailed Mann-Whitney $U$ tests were used to determine whether two groups of unpaired observations were significantly different from each other (e.g., comparing sparsely bursting and dominantly bursting cells).

We used Fisher's exact tests to assess whether there was some significant trend within the distribution of cell types along the proximodistal and radial axes of the subiculum (Fig. 4G,H). Three levels were distinguished for each axis. We performed the Fisher's exact test on the three possible pairs $(1-2,2-3$, $1-3)$ and corrected the $p$ value for significance so the overall error $\alpha$ would be 0.05 . The distribution within the two tested pairs would be considered different rather than random if the Fischer's exact test $p$ value was $<0.0167(0.05 / 3)$.

We used Fisher's exact tests to address whether spatially modulated cell types were equally distributed between the two populations of cells (Fig. 5D).

The size difference between the two clusters of subicular neurons and the small size of the group of dominantly bursting cells used for spatial information calculation [ sparsely bursting cells $(\mathrm{SB})=48 \mathrm{vs}$ dominantly bursting cells $(\mathrm{DB})=5$ ] led us to test the significance of the difference with a bootstrapping procedure. $N$ (number DB cells) values of spatial information were randomly selected from the sparsely bursting population. By repeating the procedure 1000 times, we could obtain a bootstrapped distribution of the median spatial information for sparsely bursting cells. The difference was significant if the rank of the median spatial information of dominantly bursting cells was within the fifth percentile of the bootstrapped distribution $(p \leq 0.05)$.

We wanted to test whether the spatial information encoded by bursts was significantly different from the spatial information encoded by isolated spikes. A direct comparison of spatial information values would not be appropriate, as the total number of events and smoothing parameters used for generating the rate maps can introduce bias in information measures (K. D. Harris et al., 2001). Consequently, we used a randomization method similar to K. D. Harris et al. (2001). In instances where there were less bursts than isolated spikes, we would compare information given by the $N$ bursts to the information given by 1000 random subsets of $N$ isolated spikes. Bursts were significantly more informative than isolated spikes if the 
rank of the burst spatial information exceeded the 95th percentile of the distribution of the spatial information given by the random subsets of isolated spikes.

In some instances where highly bursting cells had less isolated spikes than bursts ( $n=$ $3 / 102$ ), we compared the information given by $N$ isolated spikes to the information given by 1000 random subsets of $N$ bursts. In this case, bursts were significantly more informative than isolated spikes if the rank of the isolated spike spatial information was within the fifth percentile of the distribution of the spatial information given by the random subsets of bursts.

\section{Results}

We performed juxtacellular recordings in rats foraging for food in a $70 \times 70 \mathrm{~cm}$ open-field arena. Our data consists of 102 subicular principal cells recorded in 40 rats. Neurons were assigned as subicular cells histologically and as principal cells based on firing rates and spike waveforms (see Materials and Methods).

Sparsely and dominantly bursting cells: distinct firing patterns in vivo

Previous in vitro work (Greene and Totterdell, 1997; Staff et al., 2000; E. Harris et al., 2001; Y. Kim and Spruston, 2012) indicated the existence of distinct patterns of bursting in different types of subicular principal cells. In our in vivo recordings, we also noted distinct bursting patterns of subicular principal cells during navigation. We then categorized cells according to their burst discharge pattern during active locomotion (speed $>3 \mathrm{~cm} / \mathrm{s}$ ).

First, we performed principal component analyses of histograms of the logarithm of ISI (logISI histograms) and spike autocorrelations (Fig. 1 $A, B$ ). We focused on the first principal components $\left(\mathrm{PC}_{\mathrm{ISI}}\right.$ and $\mathrm{PC}_{\mathrm{AC}}$ ) explaining most of the variance.

$\mathrm{PC}_{\mathrm{ISI}} 1, \mathrm{PC}_{\mathrm{ISI}} 2$, and $\mathrm{PC}_{\mathrm{ISI}} 3$ explained 35,29 , and $15 \%$ of the total variance (approximately $78 \%$ total; Fig. $1 C$ ). $\mathrm{PC}_{\mathrm{AC}} 1$ and $\mathrm{PC}_{\mathrm{AC}} 2$ explained 68 and $22 \%$ of the total variance (90\% total; Fig. $1 D)$. We checked how each component was describing cell's firing patterns. First, we looked at how each parameter (each logISI bins or autocorrelation lags) loaded onto each principal component (Fig. 1E,F). Second, we ordered the logISI histograms and autocorrelation matrices according the cells' value on each component and plotted them as grayscale images (Fig. 1G,H). To summarize, the selected five parameters successfully captured most features of subicular neurons' firing patterns, isolating bursting behavior as well as other temporal aspects of their firing.

Each subicular principal cell could therefore be positioned in a 5 -dimensional space summarizing most of the firing pattern variability. From there an agglomerative cluster tree was generated based on the Euclidean distances between cells and groups of cells (Fig. 2A; see Materials and Methods for more detailed explanation) grouping cells according to their firing patterns features (Fig. $2 B, C$ ). Two distinct groups were identified: sparsely bursting cells ( $n=82$ of 102 cells, $80 \%$ ) and dominantly bursting cells ( $n=20$ of 102 cells, $\sim 20 \%$; Fig. $2 A-C$ ), named after their potential for burst initiation. Indeed, plotting each group separately showed that dominantly bursting cells displayed early peaks $(<6$ $\mathrm{ms}$ ) in both logISI histograms (Fig. 2D) and spike autocorrelations (Fig. 2E) as opposed to sparsely bursting cells. The bursting index, calculated as the proportion of ISIs $<6 \mathrm{~ms}$, was significantly higher for dominantly bursting cells than for sparsely bursting cells (Fig. $2 F$; median: $\mathrm{SB}=0.131, \mathrm{DB}=$ 0.512 , Mann-Whitney $U$ test, $p=9.10^{-12}$ ). Dominantly bursting cells had higher bursting rates than sparsely bursting cells (medians: $\mathrm{SB}=0.8 \mathrm{~Hz}, \mathrm{DB}=4.3 \mathrm{~Hz}$; Mann-Whitney $U$ test, $\left.p=1.10^{-8}\right)$. Firing rates were variable and rather high, as previously reported for subicular neurons (Sharp and Green, 1994; Lever et al., 2009; S. M. Kim et al., 2012). Firing rates were higher for dominantly bursting cells than for sparsely bursting cells (Fig. $2 G$; medians: $\mathrm{SB}=13.6 \mathrm{~Hz}, \mathrm{DB}=20.1 \mathrm{~Hz}$; Mann-Whitney $U$ test, $p=0.012$ ).

Having distinct burst indices, burst rates or firing rates between the two groups of cells was not unexpected, as our classification was established on firing pattern features. We then looked at the burst features and noticed further differences between sparsely bursting and dominantly bursting cells.

\section{Sparsely and dominantly bursting cells have distinct burst features}

Representative recordings and magnification of bursts and isolated spikes from sparsely bursting and dominantly bursting cells are shown in Figure $3 A-D$. Spike duration (from threshold to afterhyperpolarization) of sparsely bursting cells and dominantly bursting cells were not different from one another (Fig. 3E; me- 

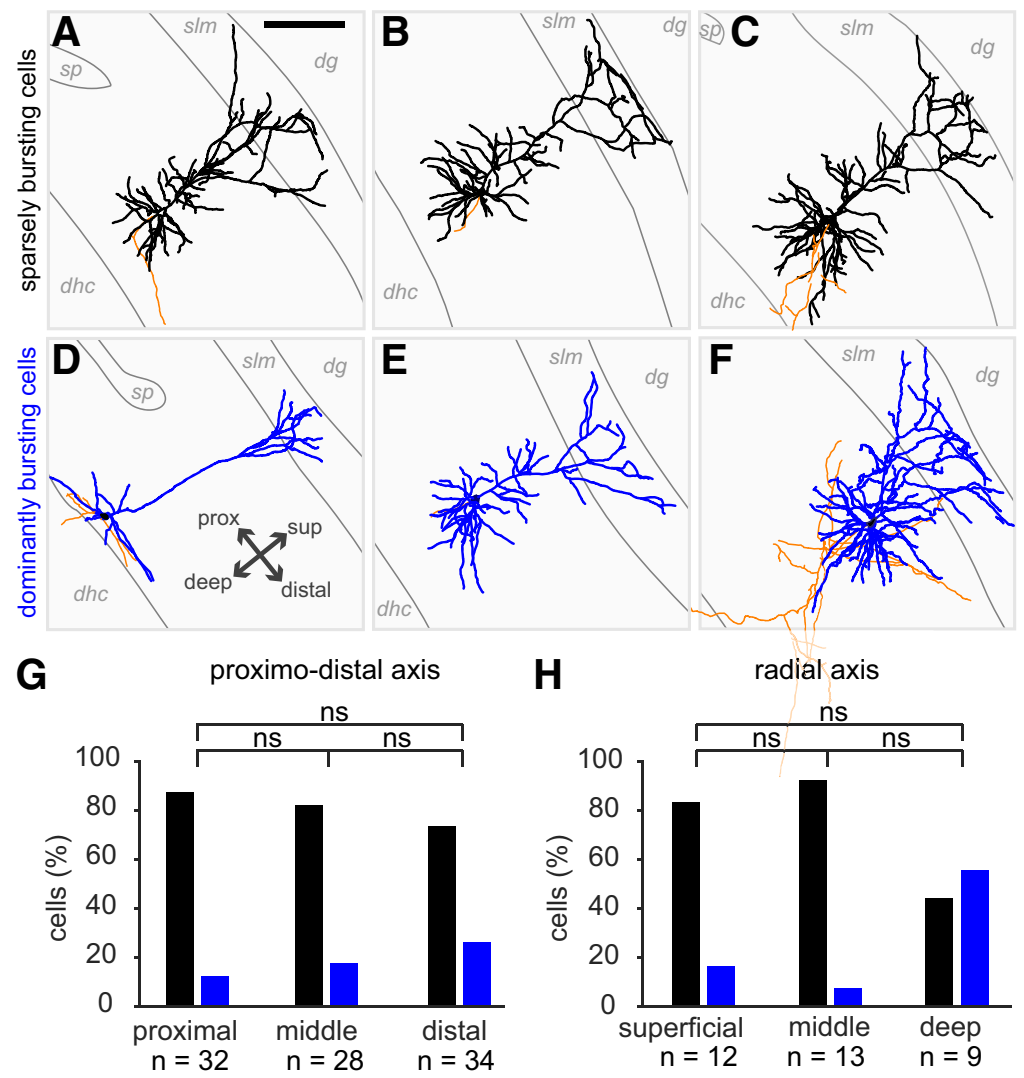

Figure 4. $A-\boldsymbol{F}$, Reconstructions of 6 subicular principal cells. Dendrites are in black (sparsely bursting cells) or blue (dominantly bursting cells) and axons are in orange. Some of the anatomical outlines have been drawn, such as (A1 stratum pyramidale (sp), the stratum lacunosum moleculare $(\mathrm{s} / \mathrm{m})$ and the limit of the subiculum with the dorsal hippocampal commissure (dhc). $\mathrm{dg}$ : dendate gyrus. All cells are oriented as indicated in panel $\boldsymbol{D}$; prox: proximal; dist: distal; sup: superficial. In $\boldsymbol{A}$, scale bar $=200 \mu \mathrm{m}$. $G$, Distribution of sparsely bursting and dominantly bursting cells along the proximo-distal axis of the subiculum. Fisher's exact tests, with level of significance corrected to be equal 0.05 in total: ns: $p>0.05 / 3$; proximal vs middle, $p=.7211$; middle vs distal $=0.5457$; superficial vs distal $=0.2183$. $\boldsymbol{H}$, Distribution of sparsely bursting and dominantly bursting cells along the radial axis of the subiculum. Fisher's exact tests (ns: $p>0.05 / 3$ ); superficial versus middle, $p=0.593$; middle versus deep $=0.0231$; superficial versus deep $=0.1588$.

dian: $\mathrm{SB}=0.824 \mathrm{~ms}, \mathrm{DB}=0.868 \mathrm{~ms}$; Mann-Whitney $U$ test, $p=$ $0.25)$. In contrast, bursts seem to be intrinsically different between the two cells types (Fig. $3 B, D$ ). Bursts spike accommodation, quantified here as the ratio of the second spike amplitude to the first spike amplitude, is slightly more pronounced in dominantly bursting cells (median: $\mathrm{SB}=0.817, \mathrm{DB}=777$, MannWhitney $U$ test, $p=0.009$ ). The proportion of bursts with $>2$ spikes (Fig. 3F; median: $\mathrm{SB}=10 \%, \mathrm{DB}=22 \%$, Mann-Whitney $U$ test, $p=1.10^{-8}$ ), as well as the average number of spikes per burst (median: $\mathrm{SB}=2.1, \mathrm{DB}=2.27$, Mann-Whitney $U$ test, $p=$ $1.10^{-7}$ ) was significantly higher in dominantly bursting cells. Finally, the intraburst intervals (ISI in bursts) are on average longer in sparsely bursting cells (Fig. $3 G$; median: $\mathrm{SB}=4.29 \mathrm{~ms}$, $\mathrm{DB}=3.66 \mathrm{~ms}$, Mann-Whitney $U$ test, $\left.p=1.10^{-11}\right)$. Overall, our analyses show that bursts are different between the two cell types, being intrinsically faster and stronger in dominantly bursting cells than in sparsely bursting cells.

\section{Sparsely and dominantly bursting cells do not segregate on an} anatomical level

So far, our analysis has shown that subicular cells could be clustered into two distinct populations with distinct bursting behavior and distinct burst features. In our analysis, we managed to morphologically identify 16 sparsely bursting cells (Fig.
$4 A-C)$ and 3 dominantly bursting cells (Fig. 4D-F). As expected from their spike shapes all could be identified as pyramidal neurons, however, our little data does not allow for firm conclusions about potential morphological differences between sparsely bursting and dominantly bursting cells.

Analysis of subicular burstiness in vitro suggested that regular spiking and intrinsic bursting pyramidal cells were not uniformly distributed along the proximodistal in the subiculum, with more bursting cells on the distal part (Greene and Totterdell, 1997; Staff et al., 2000; E. Harris et al., 2001; Y. Kim and Spruston, 2012). A recent study even suggested a sharp transition rather than a gradual evolution of bursting along the proximodistal axis (Cembrowski et al., 2018). These elements led us to check the distribution of sparsely bursting cells and dominantly bursting cells within the subiculum. We could determine the proximodistal level of 94 neurons (proximal, intermediate, or distal) as well as the depth of 30 neurons (superficial, intermediate, or deep). Our analysis showed that dominantly bursting and sparsely bursting cells could be found everywhere within the proximodistal and depth levels of the subiculum. Although dominantly bursting cells seemed to be distributed more toward distal and in deep subiculum, these trends were not significantly different from random distributions (multiple Fisher's exact tests with corrected $p$ values; see Materials and Methods; Fig. $4 G-H)$. To conclude, it seems the two populations of neurons, well defined by their bursting features, do not show clear anatomical differences.

\section{Sparsely bursting cells show a stronger spatial modulation than dominantly bursting cells}

It was found that cells with distinct bursting behavior could have distinct functions because they tend to project toward different areas (Y. Kim and Spruston, 2012; Cembrowski et al., 2018). For example, cells that project to areas involved in spatial navigation, such as the medial entorhinal cortex or presubiculum, tend to be intrinsic bursting cells when recorded in vitro. Therefore, we asked whether sparsely bursting cells and dominantly bursting cells differ in their spatial tuning properties.

We determined the spatial tuning of subicular cells only for recordings where at least $60 \%$ of the open-field arena was explored ( $n=84$ of 102). Animals' running trajectories with the superimposed spike positions (Fig. $5 A-C$, left) and the resulting rate maps (Fig. $5 A-C$, middle) were used to calculate each cell's spatial information (see Materials and Methods). Significance of the spatial information was determined using a cell-by-cell circular shuffling procedure. For a given cell, a random and consistent shift in the spike timestamp maintains the temporal structure of firing but alters the spike positions on the rat's trajectory, resulting in a new rate map and different spatial information. Applying 
this procedure 1000 times allowed us to generate a distribution of spatial information that could be obtained by chance with that cell's firing structure. A cell was then categorized as spatially modulated if its spatial information exceeded the 95th percentile of the distribution obtained by circular shuffling (Fig. $5 A-C$, right).

Figure $5 A$ is an example of a sparsely bursting cell. The spikes are mostly confined to the south section of the environment (Fig. 5A, left), and the rate map reveals a primary field in the southwest corner and a secondary field (lower rate) in the southeast corner (Fig. 5A, middle). Here, the spatial information is 0.89 bits per spike and highly significant ( $p=$ 0.002 ), because that value is far above the 95th percentile of the shuffled distribution (Fig. $5 A$, right).

Another sparsely bursting cell is shown in Figure $5 B$. Here, the spike distribution pattern is not as clearly defined, however the rate map shows a clear field all along the southern wall (Fig. $5 B$, middle). This cell also encoded significant spatial information ( 0.36 bits/spikes; $p=0.001$; Fig. $5 B$, right) and was categorized as a boundary cell with a significant border score of 0.73 ( $p=0.012$; see Materials and Methods).

A dominantly bursting cell is shown in Figure $5 C$; neither the spikes plotted on the rat's trajectory (Fig. $5 C$, left) nor the rate map (Fig. 5C, middle) suggests a sharp spatial tuning. The basal firing rate is very high and spatial information is low ( 0.06 bits per spikes), but significant ( $p=$ 0.03 ), as shown in the comparison with the shuffle distribution (Fig. $5 C$, right).

In total 51 of $84(63 \%)$ subicular cells, including 46 of $69(67 \%)$ sparsely bursting cells and 5 of 15 (33\%) dominantly bursting cells were spatially modulated (Fig. 5D). Sparsely bursting cells appear to be spatially modulated more often than dominantly bursting cells, as shown by the nonrandom distribution of spatial neurons within the two populations (Fisher's exact test, $p=0.022$ ). Looking at the proportion of sparsely bursting cells and dominantly bursting cells within spatially modulated cells (Fig. $5 E$, left), it is clear that sparsely bursting cells constitute a prominent spatial unit within the subiculum. Lastly, 17 of 51 spatially modulated cells (31\%) could be classified as boundary cells (as the cell in Fig. 5B), and all of them were sparsely bursting cells (Fig. 5E, right).

In addition to being less often spatially modulated, spatially tuned dominantly bursting cells provide lower spatial information than sparsely bursting cells (compare Figs. 5A, B, 5C; Fig. 5F; medians: $\mathrm{SB}=0.36$ bits/spike, $n=46 ; \mathrm{DB}=0.16$ bits $/$ spike, $n=$

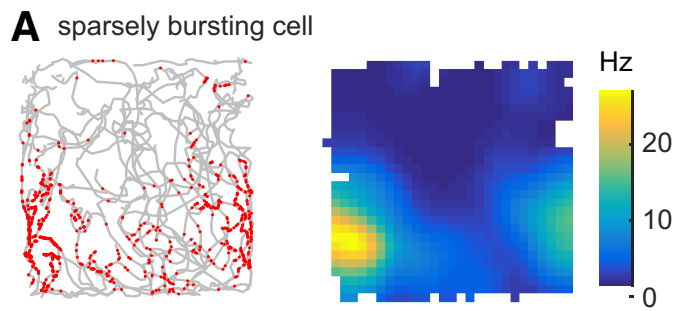

B sparsely bursting cell - boundary cell
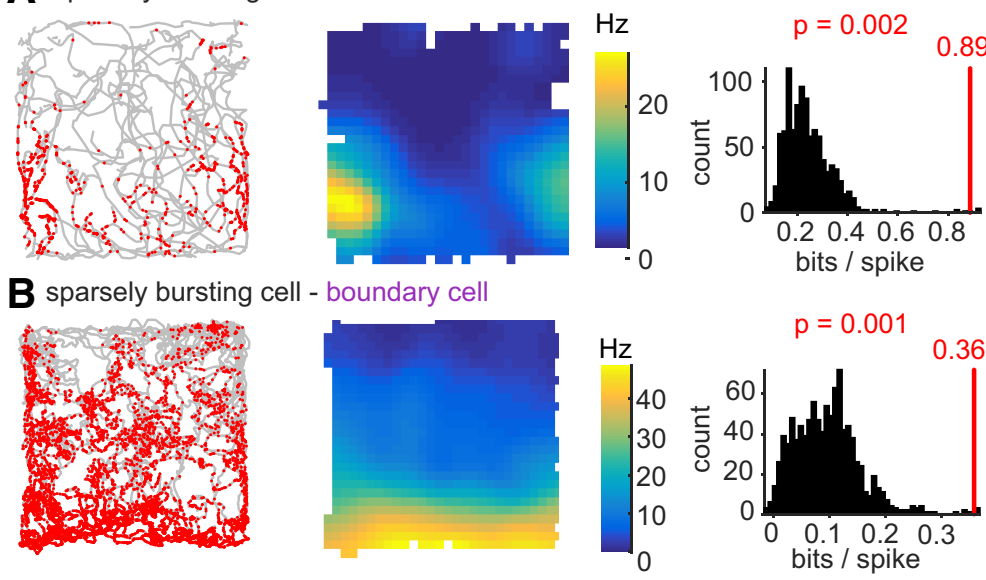

\section{C dominantly bursting cell}
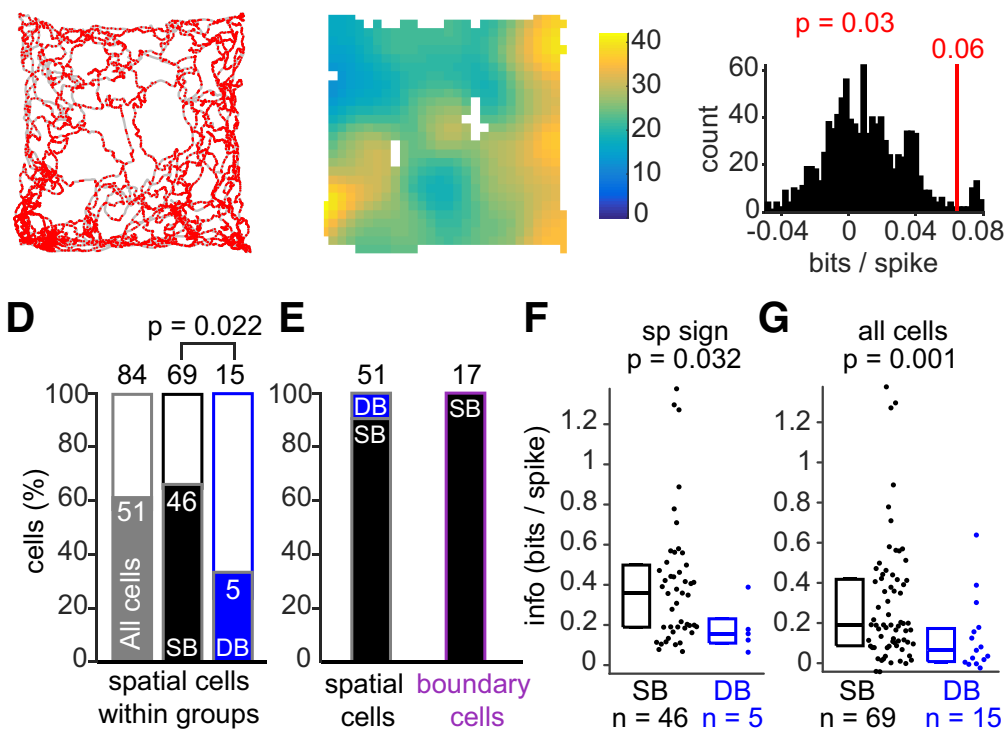

Figure 5. Sparsely bursting cells provide more spatial information than dominantly bursting cells. $\boldsymbol{A}-\boldsymbol{C}$, Left, Trajectories of rat in gray with superimposed spikes in red. Middle, Corresponding rate maps with their color-map ranging from 0 to the maximum firing rate of the cells $(\mathrm{Hz})$. Right, Cell-by-cell spatial significance analyses. Each cell's spatial information (red vertical line) was ranked within the distribution of spatial information values determined using a cell-by-cell circular shuffling procedure (black histogram, see Materials and Methods). For each cell, spatial information was declared significant if the cell's information exceeded the 95th percentile of the random distribution obtained after circular shuffling (see Materials and Methods). All the cells shown in $\boldsymbol{A}-\boldsymbol{C}$ are spatially significant ( $p<0.05$; see Materials and Methods). Neurons in $\boldsymbol{A}$ and $\boldsymbol{B}$ are sparsely bursting cells; the neuron in $\boldsymbol{C}$ is a dominantly bursting cell. The neuron in $\boldsymbol{B}$ was categorized as a boundary cell (boundary score $=0.73, p=0.01$; see Materials and Methods). $\boldsymbol{D}$, Spatial information and significance were calculated for subicular cells recorded while the animal explored (speed $>3 \mathrm{~cm} / \mathrm{s}$ ) at least $60 \%$ of the open-field arena $(n=84 / 102)$. The bar graph shows the percentage of spatially modulated cells from all subicular cells $(n=51 / 84$; gray), and then from sparsely bursting cells ( $n=46 / 69$; black) and dominantly bursting cells (5/15 cells; blue). Sparsely bursting cells are more often spatially modulated than dominantly bursting cells ( $p=0.022$ : significant Fisher's exact test). $\boldsymbol{E}$, Percentage of each cell type within spatial cell categories. Left, Sparsely bursting cells represent the majority $(n=$ 46/51) of subicular spatial units. Right, All boundary cells were sparsely bursting cells $\boldsymbol{F}$, Spatial information calculated for spatially significant sparsely bursting and dominantly bursting cells ( $p=0.032$, bootstrapping, significant) $\mathbf{G}$, Spatial information calculated for all sparsely bursting cells and dominantly bursting cells ( $p=0.001$, bootstrapping, significant).

$5 ; p=0.032$, tested with bootstrapping procedure; see Materials and Methods). Observing spatial information encoded by the entire population, including cells which are not significantly modulated (Fig. 5G), also showed a significant difference between the groups (median: $\mathrm{SB}=0.19$ bits/spike, $n=69 ; \mathrm{DB}=0.06$ bits $/$ spike, $n=15$; $p=0.001$, tested with bootstrapping procedure).

To conclude, these last results suggest that our classification of subicular neurons according to burst discharge patterns relates to significant differences in spatial coding. 


\section{Bursts provide spatial information in spatially modulated cells}

Here, we classified cells based on each cell's probability to initiate bursts, the least bursting cells being the more spatially modulated. But how is burst firing itself relevant for spatial coding, especially in cells that do not fire bursts often such as sparsely bursting cells? This prompted us to consider how bursts contributed to the transmission of spatial information.

The examples shown in Figure $5 A-C$ show that many spikes occurred outside of the main spatial firing field. To evaluate how the firing patterns contributed to the coding of spatial information at the single cell level, we separated isolated spikes and bursts into distinct plots. These examples from sparsely bursting cells (Fig. 6A-F) suggest that isolated spikes occurred in numerous locations, even though a preferred location is still evident in the rate map (Fig. $6 A-F$, isolated spikes). A strikingly different picture emerged when we only plotted bursts. Well defined firing fields emerged by looking at the bursts' positions on the trajectory and the corresponding rate map (Fig. $6 A-F$, bursts).

The difference in the number of events per group (bursts or isolated spikes) can bias spatial information values; it tends to be higher while computed on a lower number of events (K. D. Harris et al., 2001). For an individual neuron, there were typically more isolated spikes than bursts, so we compared the spatial information from the $n$ bursts with 1000 random subsets of $n$ isolated spikes. Information was considered higher in bursts if it exceeded the 95th percentile of the distribution of information calculated from the random subsets of isolated spikes (Fig. 6A-F, significance; see Materials and Methods for when there are fewer isolated spikes than bursts). The difference between isolated spikes and bursts was significant for 31 of the $46(67 \%)$ spatially modulated sparsely bursting cells and 3 of the $5(60 \%)$ spatially modulated dominantly bursting cells (Fig. $6 G, H$ ). For the 31 sparsely bursting cells with a significant difference, burst spatial information (median $=0.95$ bits/burst) was on average 2.31 times higher than isolated spike spatial information (median, 0.41 bits/isolated spike; Fig. 6I). Similarly, it was 1.83 times higher for the three dominantly bursting spatial cells, even though the burst spatial information remained among the lowest from our dataset $(0.16,0.19$, and 0.33 bits/burst; Fig. $6 I)$. Finally, 12 of 17 boundary cells $(\sim 70 \%$; Fig. $6 I)$ showed significantly more spatial information in bursts than in isolated spikes. Burst spatial information of boundary cells (median $=1.19$ bits/burst) was 2.39 times higher than their isolated spike spatial information (median $=$ 0.5 bits/isolated spike).

\section{Discussion}

We studied how burst firing related to spatial coding in the subiculum of rats. We first classified subicular neurons according to their bursting patterns and distinguished two classes of subicular neurons, a large fraction (80\%) of sparsely bursting cells and a small fraction (20\%) of dominantly bursting cells. Both cell types are located along the entire proximodistal and radial axes of the subiculum and all identified neurons were pyramidal cells. Most sparsely bursting cells were spatially modulated and we found boundary cells only within that population. Dominantly bursting cells carried little spatial information and were more rarely significantly spatially tuned. Finally, we found that bursts carried more spatial information than isolated spikes in spatially modulated neurons, especially in boundary cells.

The initial impetus for our study came from in vitro studies, which identified bursting in subicular neurons. Most interestingly, bursting was shown to be correlated with the projection target of the respective neuron (Y. Kim and Spruston, 2012) suggesting a functional relevance of the bursting phenotype. In previous studies, bursting relationship to spatial coding has been investigated in the subiculum without being clearly defined (Sharp and Green, 1994; Lever et al., 2009; Brotons-Mas et al., 2010; S. M. Kim et al., 2012). Previous reports on CA1 place cells suggested than intrinsic bursting cells, rather than regular spiking cells, were more likely to be spatially modulated (Epsztein et al., 2011). Unlike previous studies on the subiculum, we observed marked functional differences between cell classes defined by their bursting behavior. However, our results were quite opposite to those reported for CA1. Indeed, we found that dominantly bursting cells fire at higher rates and their spikes carry little spatial information, which greatly supported the idea that the overall bursting properties of subicular cells correlates with their spatial coding capabilities. We believe that the high resolution of the juxtacellular recordings, as well as our method to cluster subicular cells in distinct groups reflecting burstiness, was a key element in our findings.

However, it is not yet clear how our in vivo classification of sparsely bursting and dominantly bursting cells is related to various classifications of bursting based solely on intrinsic properties. Different in vitro studies on subicular neurons reported varying estimates for the fraction of intrinsically bursting neurons, ranging between 45 and 80\% (Mason, 1993; Stewart and Wong, 1993; Behr et al., 1996; Greene and Totterdell, 1997; Staff et al., 2000; E. Harris et al., 2001; Y. Kim and Spruston, 2012; Joksimovic et al., 2017). Only 20\% of the neurons observed in our study were of the dominantly bursting subtype. These numbers do not match previous reports and it seems unlikely that the dominantly bursting cells observed here correspond to the broad definition of intrinsic bursting cells used in in vitro studies. It seems possible that the dominantly bursting cells observed by us correspond to a subgroup of neurons with a particularly strong tendency for intrinsic bursting described in vitro. In contrast, generating bursts does not appear to be a default mode of firing for most sparsely bursting cells. These cells might be weakly bursting or regular spiking cells requiring more complex mechanisms such as the interaction of intrinsic mechanisms and synaptic inputs for bursting (Larkum, 2013).

A commonly accepted idea is that intrinsic bursting and regular spiking cells, recorded in the slice preparation, are nonuniformly distributed along the proximodistal and radial axes of the subiculum (Greene and Totterdell, 1997; E. Harris et al., 2001; Y. Kim and Spruston, 2012; Cembrowski et al., 2018). Here, we could not observe distinct anatomical distribution of sparsely bursting cells and dominantly bursting cells. Nevertheless, the fact that dominantly bursting cells can be found all along the proximodistal axis of the subiculum challenges the idea that intrinsic bursting cells are found exclusively on the distal portion of the subiculum (Cembrowski et al., 2018). The absence of a clear pattern in our data could be due to the fact that our classification does not identify the classical cell types described in vitro. However, as our data suggests that dominantly bursting cells should be a subpopulation of intrinsic bursting cells, it was surprising to find a non-uniform repartition of these cells.

Matching numbers of bursting cells between distinct studies is complicated as experimental conditions may be different from one study to another, especially because burst generation depends on many factors, which are not easy to control in vivo. Indeed, a variety of cellular mechanisms of burst generation have been suggested for subicular neurons. For instance, bursting requires T-type voltage gated calcium currents (Joksimovic et al., 
all spikes

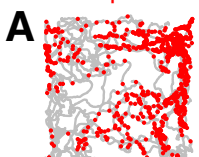

0.9 bits / spk

B

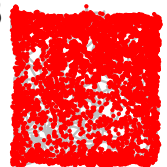

0.13 bits / spk

C

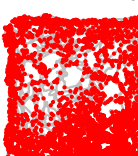

0.52 bits / spk

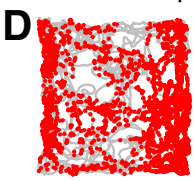

0.59 bits / spk

E

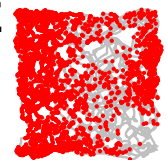

0.49 bits / spk

F

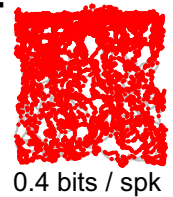

isolated spikes

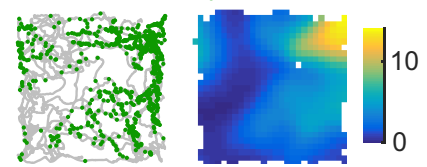

0.9 bits / isolated spike

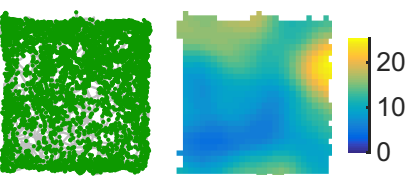

0.12 bits / isolated spike
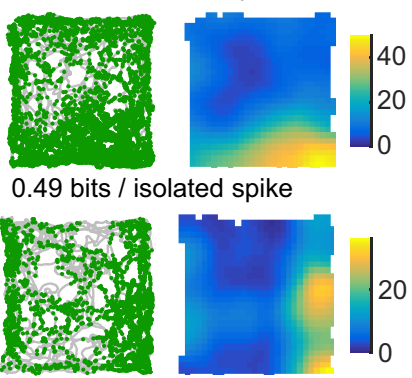

0.58 bits / isolated spike

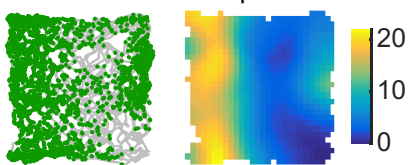

0.48 bits / isolated spike

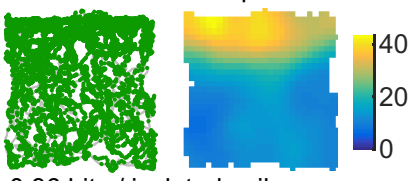

0.36 bits / isolated spike
G

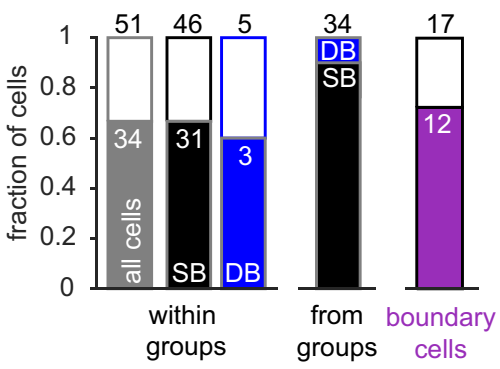
burst info > isol spike info

groups groups cells
H

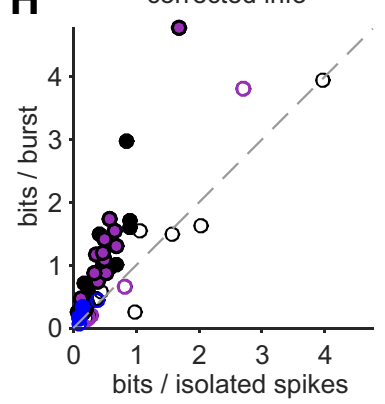

bursts

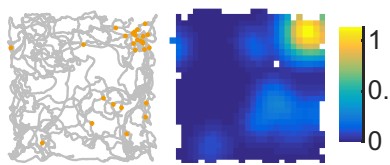

1.59 bits / burst

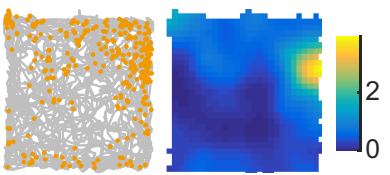

0.48 bits / burst

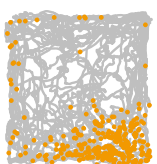

1.42 bits / burst

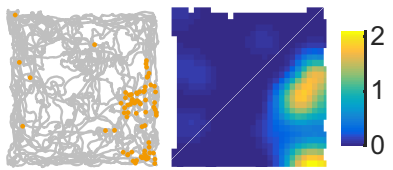

1.74 bits / burst

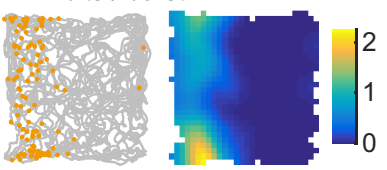

1.21 bits / burst

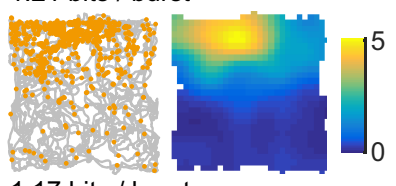

1.17 bits / burst
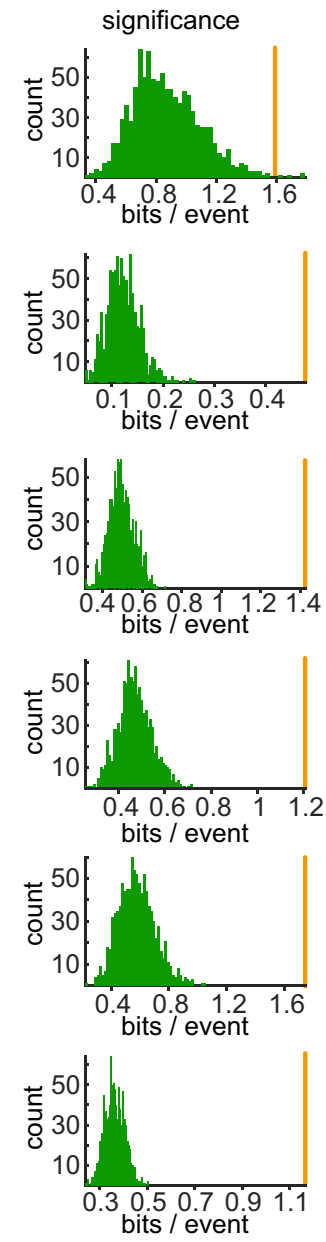

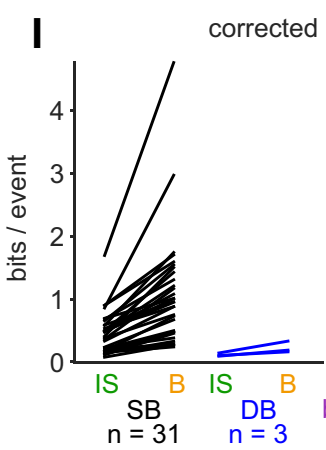

Figure 6. Sharp spatial tuning of burst firing in spatially modulated sparsely bursting cells. $\boldsymbol{A}-\boldsymbol{F}$, Example plots of sparsely bursting spatial neurons. Spikes, Spikes (red dots) superimposed onto the animal's trajectory (gray line). Isolated spikes, Isolated spikes (green dots) superimposed onto the animal's trajectory (gray line) and corresponding rate map; corrected spatial information below. Bursts, Bursts (orange dots) on animals' trajectories (gray line) and corresponding burst rate maps; spatial information below. Each color-map ranges from 0 to the rate map maximum rate (Hz). Significance, Results of the bootstrapping used to determine significance of burst spatial information compared with isolated spike information. The orange line represents spatial information calculated from the $N$ bursts fired by each cell and the green histogram shows the distribution of spatial information calculated from 1000 random samples of $N$ isolated spikes. Cells in $\boldsymbol{C}-\boldsymbol{F}$ are boundary cells. G, Fraction of cells where burst spatial information is significantly higher than isolated spike spatial information. Within groups, Proportion of all spatial cells, sparsely bursting spatial cells and dominantly bursting spatial cells with a significant difference. From groups, Proportion sparsely bursting cells and dominantly bursting cells in cells showing a significant difference. Boundary cells, Proportion of boundary cells with a significant difference. $\boldsymbol{H}$, Information per burst versus information per isolated spike for spatially modulated neurons $(n=46$ sparsely bursting cells, black circles and purple circles corresponding to boundary cells; $n=5$ dominantly bursting cells, blue circle). Solid circles indicate cells with a significant increase of spatial information between bursts and isolated spikes ( $n=31 / 46$ for sparsely bursting cells including $n=12 / 17$ boundary cells and $n=3 / 5$ for dominantly bursting cells). I, Spatial information per isolated spike and bursts only for spatial cells with a significant difference, with sparsely bursting cells in black and dominantly bursting cells in blue and boundary cells in purple. Corrected info, Spatial information calculated using similar numbers of bursts and isolated spikes (from the bootstrapping).

2017) that can be affected by neuromodulatory signals, such as serotonin, which was shown to downregulate T-type channels and burst generation in the subiculum (Petersen et al., 2017).

As the output structure of the hippocampus, the subiculum sends high-frequency, but rather imprecise, spatial coding to downstream areas. Indeed, peak frequencies of subicular spatial neurons are rather high compared with CA1, as are their baseline frequencies (Sharp, 1997, 2006; Y. Kim and Spruston, 2012). Nevertheless, spatial signals can be refined if the precise firing pattern of subicular neurons is taken into consideration. Indeed, 
isolated spikes and bursts are functionally distinct units of information in most spatially modulated neurons ( $\sim 60 \%)$, especially in cells encoding environmental boundaries. Although bursts were often fired in well defined "place" fields, isolated spikes were more spatially dispersed. Such differential coding by isolated spikes and bursts is similar to information processing in sensory systems (Krahe and Gabbiani, 2004). Nonetheless, our findings are remarkably different from CA1, where bursts sharpen spatial information in only $\sim 20 \%$ of place cells (K. D. Harris et al., 2001). Such a difference shows the relevance of burst firing in noisy spatial cells, such as subicular cells, compared with sharply tuned CA1 place cells.

Bursts and isolated spikes are two units of information that can be read differentially through the interaction between shortterm plasticity and postsynaptic integrative properties (Lisman, 1997; Izhikevich et al., 2003). The spatial information conveyed by a burst could be decoded by the summation of excitatory events at facilitating synapses whereas poorly tuned spatial inputs could be better decoded through depressing synapses (Lisman, 1997). This should be the case for long-range projections and could as well define functional subcircuits within the local microcircuit (Simonnet et al., 2017; Nassar et al., 2018). The ongoing activity and resonating properties of targeted neurons could define the response to these signals (Izhikevich et al., 2003). However, the neuronal targets of subicular spatial neurons and how these integrate and convert multiplexed signals at the cellular and microcircuit levels are unknown elements. These will need to be resolved for a better understanding of the subicular role in distributing hippocampal output spatial codes.

\section{References}

Amaral DG, Witter MP (1989) The three-dimensional organization of the hippocampal formation: a review of anatomical data. Neuroscience 31: 571-591.

Barry C, Lever C, Hayman R, Hartley T, Burton S, O'Keefe J, Jeffery K, Burgess N (2006) The boundary vector cell model of place cell firing and spatial memory. Rev Neurosci 17:71-97.

Behr J, Empson RM, Schmitz D, Gloveli T, Heinemann U (1996) Electrophysiological properties of rat subicular neurons in vitro. Neurosci Lett 220:41-44.

Bjerknes TL, Moser EI, Moser MB (2014) Representation of geometric borders in the developing rat. Neuron 82:71-78.

Böhm C, Peng Y, Maier N, Winterer J, Poulet JF, Geiger JR, Schmitz D (2015) Functional diversity of subicular principal cells during hippocampal ripples. J Neurosci 35:13608-13618.

Brotons-Mas JR, Montejo N, O’Mara SM, Sanchez-Vives MV (2010) Stability of subicular place fields across multiple light and dark transitions: stability of subicular place fields. Eur J Neurosci 32:648-658.

Brotons-Mas JR, Schaffelhofer S, Guger C, O'Mara SM, Sanchez-Vives MV (2017) Heterogeneous Spatial Representation by Different Subpopulations of Neurons in the Subiculum. Neuroscience 343:174-189.

Cembrowski MS, Phillips MG, DiLisio SF, Shields BC, Winnubst J, Chandrashekar J, Bas E, Spruston N (2018) Dissociable structural and functional hippocampal outputs via distinct subiculum cell classes. Cell 173: 1280-1292.e18.

Coletta S, Zeraati R, Nasr K, Preston-Ferrer P, Burgalossi A (2018) Interspike interval analysis and spikelets in presubicular head-direction cells. J Neurophysiol 120:564-575.

Ebbesen CL, Reifenstein ET, Tang Q, Burgalossi A, Ray S, Schreiber S, Kempter R, Brecht M (2016) Cell type-specific differences in spike timing and spike shape in the rat parasubiculum and superficial medial entorhinal cortex. Cell Rep 16:1005-1015.

Epsztein J, Brecht M, Lee AK (2011) Intracellular determinants of hippocampal CA1 place and silent cell activity in a novel environment. Neuron 70:109-120.

Galani R, Weiss I, Cassel JC, Kelche C (1998) Spatial memory, habituation, and reactions to spatial and nonspatial changes in rats with selective le- sions of the hippocampus, the entorhinal cortex or the subiculum. Behav Brain Res 96:1-12.

Greene JR, Totterdell S (1997) Morphology and distribution of electrophysiologically defined classes of pyramidal and nonpyramidal neurons in rat ventral subiculum in vitro. J Comp Neurol 380:395-408.

Hafting T, Fyhn M, Molden S, Moser MB, Moser EI (2005) Microstructure of a spatial map in the entorhinal cortex. Nature 436:801-806.

Hardcastle K, Ganguli S, Giocomo LM (2015) Environmental boundaries as an error correction mechanism for grid cells. Neuron 86:827-839.

Harris E, Witter MP, Weinstein G, Stewart M (2001) Intrinsic connectivity of the rat subiculum: I. dendritic morphology and patterns of axonal arborization by pyramidal neurons. J Comp Neurol 435:490-505.

Harris KD, Hirase H, Leinekugel X, Henze DA, Buzsáki G (2001) Temporal interaction between single spikes and complex spike bursts in hippocampal pyramidal cells. Neuron 32:141-149.

Hartley T, Burgess N, Lever C, Cacucci F, O'Keefe J (2000) Modeling place fields in terms of the cortical inputs to the hippocampus. Hippocampus 10:369-379.

Ishizuka N (2001) Laminar organization of the pyramidal cell layer of the subiculum in the rat. J Comp Neurol 435:89-110.

Izhikevich EM, Desai NS, Walcott EC, Hoppensteadt FC (2003) Bursts as a unit of neural information: selective communication via resonance. Trends Neurosci 26:161-167.

Joksimovic SM, Eggan P, Izumi Y, Joksimovic SL, Tesic V, Dietz RM, Orfila JE, DiGruccio MR, Herson PS, Jevtovic-Todorovic V, Zorumski CF, Todorovic SM (2017) The role of T-type calcium channels in the subiculum: to burst or not to burst?: T-channels regulate neuronal excitability in the subiculum. J Physiol 595:6327-6348.

Kim SM, Ganguli S, Frank LM (2012) Spatial information outflow from the hippocampal circuit: distributed spatial coding and phase precession in the subiculum. J Neurosci 32:11539-11558.

Kim Y, Spruston N (2012) Target-specific output patterns are predicted by the distribution of regular-spiking and bursting pyramidal neurons in the subiculum. Hippocampus 22:693-706.

Ko D, Wilson CJ, Lobb CJ, Paladini CA (2012) Detection of bursts and pauses in spike trains. J Neurosci Methods 211:145-158.

Krahe R, Gabbiani F (2004) Burst firing in sensory systems. Nat Rev Neurosci 5:13-23

Krupic J, Bauza M, Burton S, Barry C, O’Keefe J (2015) Grid cell symmetry is shaped by environmental geometry. Nature 518:232-235.

Larkum M (2013) A cellular mechanism for cortical associations: an organizing principle for the cerebral cortex. Trends Neurosci 36:141-151.

Latuske P, Toader O, Allen K (2015) Interspike intervals reveal functionally distinct cell populations in the medial entorhinal cortex. J Neurosci 35: 10963-10976.

Lee SA, Miller JF, Watrous AJ, Sperling MR, Sharan A, Worrell GA, Berry BM, Aronson JP, Davis KA, Gross RE, Lega B, Sheth S, Das SR, Stein JM, Gorniak R, Rizzuto DS, Jacobs J (2018) Electrophysiological signatures of spatial boundaries in the human subiculum. J Neurosci 38:3265-3272.

Lever C, Burton S, Jeewajee A, O’Keefe J, Burgess N (2009) Boundary vector cells in the subiculum of the hippocampal formation. J Neurosci 29:97719777.

Lisman JE (1997) Bursts as a unit of neural information: making unreliable synapses reliable. Trends Neurosci 20:38-43.

Mason A (1993) Electrophysiology and burst-firing of rat subicular pyramidal neurons in vitro: a comparison with area CA1. Brain Res 600:174-178.

Morris RG, Schenk F, Tweedie F, Jarrard LE (1990) Ibotenate lesions of hippocampus and/or subiculum: dissociating components of allocentric spatial learning. Eur J Neurosci 2:1016-1028.

Muessig L, Hauser J, Wills TJ, Cacucci F (2015) A developmental switch in place cell accuracy coincides with grid cell maturation. Neuron 86:11671173.

Naber PA, Witter MP (1998) Subicular efferents are organized mostly as parallel projections: a double-labeling, retrograde-tracing study in the rat. J Comp Neurol 393:284-297.

Nassar M, Simonnet J, Huang LW, Mathon B, Cohen I, Bendels MHK, Beraneck M, Miles R, Fricker D (2018) Anterior thalamic excitation and feedforward inhibition of presubicular neurons projecting to medial entorhinal cortex. J Neurosci 38:6411-6425.

O'Keefe J, Burgess N (1996) Geometric determinants of the place fields of hippocampal neurons. Nature 381:425-428.

O'Keefe J, Dostrovsky J (1971) The hippocampus as a spatial map: prelim- 
inary evidence from unit activity in the freely-moving rat. Brain Res $34: 171-175$.

O'Mara S (2005) The subiculum: what it does, what it might do, and what neuroanatomy has yet to tell us. J Anat 207:271-282.

Petersen AV, Jensen CS, Crépel V, Falkerslev M, Perrier JF (2017) Serotonin regulates the firing of principal cells of the subiculum by inhibiting a T-type $\mathrm{Ca}^{2+}$ current. Front Cell Neurosci 11:60.

Pinault D (1996) A novel single-cell staining procedure performed in vivo under electrophysiological control: morpho-functional features of juxtacellularly labeled thalamic cells and other central neurons with biocytin or neurobiotin. J Neurosci Methods 65:113-136.

Roy DS, Kitamura T, Okuyama T, Ogawa SK, Sun C, Obata Y, Yoshiki A, Tonegawa S (2017) Distinct neural circuits for the formation and retrieval of episodic memories. Cell 170:1000-1012.e19.

Sharp PE (1997) Subicular cells generate similar spatial firing patterns in two geometrically and visually distinctive environments: comparison with hippocampal place cells. Behav Brain Res 85:71-92.

Sharp PE (2006) Subicular place cells generate the same "map" for different environments: comparison with hippocampal cells. Behav Brain Res 174:206-214.

Sharp PE, Green C (1994) Spatial correlates of firing patterns of single cells in the subiculum of the freely moving rat. J Neurosci 14:2339-2356.

Simonnet J, Nassar M, Stella F, Cohen I, Mathon B, Boccara CN, Miles R,
Fricker D (2017) Activity dependent feedback inhibition may maintain head direction signals in mouse presubiculum. Nat Commun 8:16032.

Skaggs WE, McNaughton BL, Gothard KM (1993) An informationtheoretic approach to deciphering the hippocampal code. In: Advances in neural information processing systems, pp. 1030-1037. San Francisco: Morgan Kaufmann.

Solstad T, Boccara CN, Kropff E, Moser MB, Moser EI (2008) Representation of geometric borders in the entorhinal cortex. Science 322:18651868 .

Staff NP, Jung HY, Thiagarajan T, Yao M, Spruston N (2000) Resting and active properties of pyramidal neurons in subiculum and CAl of rat hippocampus. J Neurophysiol 84:2398-2408.

Stewart M, Wong RK (1993) Intrinsic properties and evoked responses of guinea pig subicular neurons in vitro. J Neurophysiol 70:232-245.

Tang Q, Brecht M, Burgalossi A (2014) Juxtacellular recording and morphological identification of single neurons in freely moving rats. Nat Protoc 9:2369-2381.

von Heimendahl M, Rao RP, Brecht M (2012) Weak and nondiscriminative responses to conspecifics in the rat hippocampus. J Neurosci 32:21292141.

Ward JH (1963) Hierarchical grouping to optimize an objective function. J Am Stat Assoc 58:236-244.

Witter MP (2006) Connections of the subiculum of the rat: topography in relation to columnar and laminar organization. Behav Brain Res 174:251-264. 